\title{
Prólogo a la versión española del Curso de lingüística general
}

\author{
Prologue to the Spanish version of the General Linguistics Course
}

Amado Alonso

Con este prólogo quisiera hacer ver al lector cómo la ciencia es tarea que se va cumpliendo sin detenerse nunca, y cómo puede un sabio ser tan ilustre por los problemas que se plantea y resuelve como por los que obliga a sus colegas y sucesores a replantear y resolver.

El Curso de lingüística general de Ferdinand de Saussure es el mejor cuerpo organizado de doctrinas lingüísticas que ha producido el positivismo; el más profundo y a la vez el más clarificador. Es la suya una posición científica positivista, sí; pero la doctrina de Saussure es algo más que el resumen y coronación de una escuela científica superada; lo que aquí se nos da, o lo mejor y más personal de lo que se nos da, se salva de la liquidación del positivismo, incorporado perdurablemente al progreso de la ciencia. Pienso sobre todo en el riguroso y sistemático deslindamiento de dos parejas de conceptos lingüísticos, una que atañe directamente al objeto de estudio, y secundariamente a los métodos respectivos; la otra, al revés: la lengua como sistema de expresiones convencionales usado por una comunidad, y el habla como el uso individual del sistema; la lingüística sincrónica, que estudia la constitución y funcionamiento de un sistema, y la lingüística diacrónica, que estudia su evolución (ver los índices).
Piensoensurigurosaconcepciónestructuralista de las lenguas como sistemas en que todos los términos son solidarios, y en el concepto complementario - más bien implicado- de «valor» (el valor de una unidad lingüística está determinado, limitado y precisado por el de las otras entidades del sistema: tibio, lo que no es frío ni caliente; domini, genitivo por su oposición con dominus, domino, dominum, etc.). El valor, que consiste en la solidaridad e interdependencia de una significación con las otras significaciones, emana del sistema e implica la presencia concreta del sistema en cada uno de sus elementos; la significación, dice Saussure, no se sale del elemento aislado y de su idea representada ${ }^{1}$. Primera vez que se enfoca el problema del significar en el terreno concreto de la lengua, no ya en el abstracto de la lógica. Y Saussure completa su concepto de la lengua-sistema con una visión personal de las relaciones entre la palabra y el pensamiento, y entre la materia acústica y los sonidos lingüísticos: antes de la formulación idiomática, nuestro pensamiento no es más que una masa amorfa; sólo los signos lingüísticos nos hacen distinguir dos ideas de manera clara y constante. La sustancia fónica tampoco es en sí más que una informe materia plástica que sólo gracias a la lengua se divide a su vez en partes distintas para proporcionar

1 Este concepto lingüístico de valor ha sido revolucionario y de una incalculable fecundidad científica: el funcionamiento entero de una lengua consiste en el juego de identidades y diferencias; valores y sus oposiciones. El concepto de significación, en cambio, no puede parangonarse en rigor científico con el que ya para 1900 había elaborado Edmund Husserl con su método fenomenológico: «la referencia intencional al objeto», «el modo determinado de mentar el objeto». Véase E. HUSSERL, Investigaciones lógicas, tomo II, Investigación primera; Expresión y significación. Madrid, 1929, págs. 31-109 (ed. de la Revista de Occidente). En la segunda edición alemana, 1913, Husserl reelaboró mucho la primera redacción de 1900, pero esta Investigación sobre los signos fue la menos tocada. La doctrina lingüística de los valores (Saussure) tiene también su correspondencia lógica en el $\S 13$ de la Investigación primera de Husserl. 
los significantes que el pensamiento necesita. El sonido no es un mero medio fónico material para la expresión de las ideas; en la lengua, sonido y pensamiento llegan por su unión a delimitaciones recíprocas de unidades; el pensamiento sonido implica divisiones y la lengua elabora sus unidades al constituirse entre dos masas amorfas (pág. 136 y sigs.). Tal es lo que Saussure entiende por articulación: la lengua es el dominio de las articulaciones. Este concepto de las relaciones entre lengua y pensamiento, mucho más profundo que el meramente asociacionista de los Neogramáticos ${ }^{2}$, está en la misma dirección que la «forma interior de lenguaje» de Humboldt, la «actitud categorial» o clasificatoria de la razón-lenguaje de Bergson y la filosofía de las formas simbólicas de E. Cassirer. Bien es verdad que, fuera del capítulo donde se expone, no interviene ya esta concepción en la marcha del libro, sino más bien el asociacionismo herbartiano de los Neogramáticos ${ }^{3}$; pero es evidente que esta incongruencia del Curso es achacable a la prematura muerte del autor.

No hay aspecto de la lingüística, de los estudiados en el Curso, al que Saussure no haya aportado claridad y profundidad de conocimiento, unas veces llegando ya a la interpretación satisfactoria, otras obligando con sus proposiciones a los lingüistas posteriores a superarlo: en fonología, el grado de abertura de los sonidos como criterio de clasificación, la oposición de sonidos implosivos (la s de es) y explosivos (la s de se) y su utilísima teoría de la sílaba; en la diacronía*, las distinciones entre cambio fonético y analogía, entre analogía y aglutinación, lingüística externa y lingüística interna, lingüística prospectiva y retrospectiva; en la sincronía, el discernimiento entre lengua oral y lengua literaria, entre oposición y diferencia, entre relaciones sintagmáticas o in praesentia y asociativas o in absentia; en la vida historicogeográfica de idiomas y dialectos, el espíritu de campanario o fuerza particularista y el intercambio o fuerza unificadora. Con razón se ha llamado a Saussure el gran deslindador de antinomias ${ }^{4}$.

Una de las características de la mentalidad de Saussure es que cada distinción y cada delimitación de hechos está ya como encarnada en sus exigencias metodológicas, de modo que sus doctrinas han nacido más de las necesidades técnicas de la investigación que de la contemplación filosófica del objeto. Las ventajas inmediatas que los lingüistas hallan en un libro de este carácter son obvias, sobre todo si se añade a lo expuesto el rigor mental de los análisis y de las deducciones como si Saussure, al fin buen positivista, quisiera competir con las ciencias físicas. Para remate, es extraordinario el poder pedagógico de la exposición, con su estilo de antinomias, sus comparaciones tan sugestivas y sus dibujos. Sí; éste será siempre un libro clásico en la ciencia del lenguaje. Su influjo en la investigación particular de todas partes ha sido grande, pero sobre todo en Francia y la Suiza francesa, donde lingüistas tan eminentes como Antoine Meillet, Joseph Vendryes, Charles Bally y Albert Sechehaye lo han acatado como el código supremo del saber teórico y de la orientación en los métodos. "Ortodoxos saussureanos», es expresión que alguno de ellos ha usado y que a todos ha placido.

Por supuesto, no todos son triunfos, y la crítica no ha tardado en descubrir los defectos de tales virtudes. Ya hemos insinuado uno: la doctrina de Saussure no tiene base filosófica meditada por él; le bastó con tomar, sin inquietud personal alguna, la positivista. Y como el positivismo, sobre todo el practicado, ya quería ser más científico que filosófico, receloso de hurgar en los últimos fundamentos de cada ciencia, las

2 El teórico de los Neogramáticos, HERMANN PAUL, Prinzipien der Sprachgeschichte, concibe estas relaciones como una mera asociación de la imagen acústica (la palabra) con la idea, de existencia autónoma, según la psicología asociacionista de Herbart que presidió tranquila estos estudios durante ochenta años.

3 Especialmente visible en su exposición del circuito del habla.

4 En realidad, como conjunto y estilo mental, las antinomias de Saussure proceden de Hegel a través del lingüista hegeliano VICTOR HENRY, Antinomies linguistiques. 
limitaciones de las doctrinas de Saussure se explican por las de la base aceptada.

Para ser más breves y claros leamos el capítulo III de la Introducción, «Objeto de la lingüística»: « ...el fenómeno lingüístico presenta perpetuamente dos caras que se corresponden sin que la una valga más que gracias a la otra»: la lengua, o sistema adquirido, y el habla, el uso individual del sistema; el estado de un sistema y su historia; aun la palabra tiene su lado fisicofisiológico, el sonido, y su lado mental, la idea. ¿Cuál será, pues, el objeto de la lingüística? «Tomado en su totalidad, el lenguaje es multiforme y heteróclito; a caballo en diferentes dominios, a la vez físico, fisiológico y psíquico, pertenece además al dominio individual y al social; no se deja clasificar en ninguna de las categorías de fenómenos humanos, porque no se sabe cómo desembrollar su unidad. La lengua por el contrario es algo enterizo y un principio de clasificación». También Karl Vossler ve en el lenguaje tales dualidades, y su paralelo con Saussure, ya esbozado en nuestro prólogo a su Filosofía del lenguaje, de esta colección, puede ayudarnos ahora a comprender de una vez las virtudes y las limitaciones del Curso. Esas dualidades fuerzan a Vossler a ver el lenguaje como una estructura polar, y el objeto de su lingüística es la perpetua corriente de doble dirección. Si el objeto concreto es complejo, el objeto de estudio es también su complejidad.

Saussure ve la complejidad del lenguaje tan bien como Vossler, pero la rehuye como objeto de estudio, $y$, en busca de uno deslindado y homogéneo, da con «la lengua», un autónomo sistema de signos, separado de su uso e independiente de los individuos que lo usan. Los otros aspectos se pueden también estudiar, pero como meramente adicionales, como «externos a la lengua» y por tanto a la lingüística. Todo se paga: la lingüística de Saussure llega a una sorprendente claridad y simplicidad, pero a fuerza de eliminaciones, más aún, a costa de descartar lo esencial en el lenguaje (el espíritu) como fenómeno específicamente humano.
En parte por dar rigor científico a esta delimitación del objeto, en parte por sor la simplificación eliminatoria rasgo dominante en su estilo mental, Saussure concibe las dualidades apuntadas como antinomias irreductibles. Pero ¿lo son realmente la lengua y el habla, la diacronía y la sincronía? Saussure nos ha hecho ver que son aspectos discernibles del lenguaje y le agradecemos el grande progreso que los métodos de investigación han sacado de ello; pero ¿son objetos separados, y más, como quería Saussure, objetos sin contacto directo posible? «Un hecho diacrónico es un suceso que tiene su razón de ser en sí mismo; las consecuencias sincrónicas particulares que se puedan derivar le son completamente extrañas» (pág. 110). Los plurales ingleses y alemanes de inflexión son buen ejemplo: foot-feet, goose-geese, GastGäste, Hand-Hände; en anglo-sajón y en antiguo alto alemán, los plurales de estas series tenían el signo regular de -i; *fōti, *gōsi, gasti, hanti; a acción metafónica de la -i inflexionó la vocal precedente con proceso puramente fonético ${ }^{5}$; luego la -i se hizo e en alemán y desapareció en inglés; y he aquí un nuevo estado morfológico en ambos sistemas, absolutamente imprevisto en los cambios fonéticos respectivos. Y Saussure sigue discurriendo: «Los hechos diacrónicos ni siquiera tienden a cambiar el sistema. No se ha querido pasar de un sistema de relaciones a otro [de gast-gasti a Gast-Gäste, etc.]; la modificación no recae sobre la ordenación, sino sobre los elementos ordenados.

Aquí nos volvemos a encontrar con un principio ya enunciado: el sistema no se modifica directamente nunca; en sí mismo es inmutable; sólo sufren alteración ciertos elementos sin atención a la solidaridad que los ata al conjunto». Los hechos de la serie diacrónica y los de la sincrónica son, por lo tanto, de órdenes heterogéneos, "pues ya hemos establecido que los cambios se producen fuera de toda intención. Por el contrario, el hecho de sincronía es siempre significativo [= intencional]; siempre pone en relación dos términos simultáneos; no es Gäste lo que expresa el plural, sino la oposición Gast-

5 No por plurales; lo mismo que en ellos obró la -i en la flexión verbal: el antiguo alto alemán tragit es hoy trägt. 
Gäste. En el hecho diacrónico, al revés: no interesa más que un solo término, y para que aparezca una forma nueva (Gäste), es necesario que la antigua (Gasti) le ceda el lugar». Esta sorprendente concepción de las relaciones - de la falta de relación directa - entre la diacronía y la sincronía deslumbró a algunos, desconcertó a otros y por fin desató la oposición más viva y general ${ }^{6}$.

En el primer Congreso Internacional de Lingüistas, La Haya, 1928, los fonólogos R. Jakobson (Praga), S. Karcevsky (Ginebra) y N. Trubetzkoy (Viena) llevan el primer ataque a fondo. Estos fonólogos del Círculo Lingüístico de Praga tienen para los sonidos idiomáticos la misma concepción estructuralista que Saussure para el sistema de la lengua; los sonidos de un idioma forman un sistema en el mismo sentido que las formas gramaticales o las palabras ${ }^{7}$. Y la proposición de los fonólogos rezaba: «La antinomia de la fonología sincrónica y de la fonética diacrónica quedará suprimida en cuanto se consideren los cambios fonéticos en función del sistema fonológico que los sufre. Hay que plantear el problema de la finalidad con que ocurren esos cambios. Y la fonética histórica se transformará así en una historia de la evolución de un sistema fonológico». De los Neogramáticos, a quienes tanto se oponía, arrastró Saussure «la concepción de los cambios fonéticos como fortuitos e involuntarios», "como una serie de

6 Aunque no elaborada en conceptos científicos tan estrictamente definidos, la dualidad de lingüística histórica y lingüística estática era una de las que regían como base en los estudios de los Neogramáticos (Brugmann, Osthoft, Braune, Sievers, H. Paul, Leskien, Meyer-Lübke; finales del siglo XIX y después), y aun antes en el ruso Baudouin de Courtenay y en el italiano Ascoli. Cfr. ROMAN JAKOBSON. La scuola lingüistica di Praga, en La Cultura, Milano, XII, 1933, pág. 637, y B. A. TERRACINI, Paleontología ascoliana e lingüistica storica, en la Silloge lingüistica dedicata alia memoria di Graziadio Isaia Ascoli, Turín, 1929, págs. 649-655. La distinción sistemática y precisa entre la lingüística «estática» (sincrónica) y la «histórica» (diacrónica) se debe antes que a otro alguno al filósofo checo T. G. MASARYK, Základové konkretné logiki (1885), con traducción alemana en 1887: Versuch einer conkreten Logik (Ensayo de una lógica concreta), ap. JAKOBSON, l.c.. Pero, aunque algunos lingüistas checos hayan seguido directamente a Masaryk, la introducción de estos conceptos rigurosos en el campo de la lingüística es obra de Saussure, que sin duda los elaboró independientemente.

7 Tanto, que los fieles discípulos del maestro ginebrino reclaman la filiación saussureana de la nueva disciplina. La verdad es que Saussure, que distinguió bien en el estudio de los sonidos la sincronía y la diacronía (fonología y fonética, en su terminología), no vio en ellos su otra dualidad de lengua y habla; no los vio más que en la realización material del habla: «la fonología - hay que repetirlo - no es más que una disciplina auxiliar y no se refiere más que al habla» (pág. 59). Ya había dicho antes (pág. 45): «Los órganos de la voz son tan exteriores a la lengua como los aparatos eléctricos que sirven para transmitir el alfabeto Morse son ajenos a ese alfabeto; y la fonación, es decir, la ejecución de las imágenes acústicas, no afecta en nada al sistema mismo». Evidentemente; pero esas «imágenes acústicas» («fonemas ideales», como los de Praga dicen menos psicológicamente) sí que pertenecen al sistema. De la misma manera que existe, según Saussure, el sistema de formas gramaticales y léxicas aparte de su realización en el habla, así existe el sistema de fonemas. Y los fonemas ostentan el mismo carácter de «valores solidarios», pues su función de signos se determina por análogo juego de correspondencias y oposiciones. La nueva disciplina utiliza ahora los sinónimos fonética y fonología con otro reparto; la fonética se ocupa de los sonidos lingüísticos en su constitución material: materia física y actividad fisiológica; la fonología los estudia en su constitución intencional de signo. Como materia, un sonido existe lo mismo aislado que agrupado; como signo, sólo funciona en relación con los otros del sistema, como valor solidario. La realización fonética es la que no se sale del habla (Saussure); pero el sistema fonológico realizado, ése pertenece a la lengua. Así resulta que la nueva doctrina fonológica es más saussureana que la de Saussure, por encuadrar mejor en la concepción general saussureana de la lengua como sistema de valores. Pero la nueva fonología no arrancó, o no arrancó sólo, de Saussure, y tiene mayor deuda directa con el ruso Baudouin de Courtenay y con el checo T. G. Masaryk, ambos del último tercio del siglo pasado, aunque, sin duda, el Curso contribuyó grandísimamente a elaborar esta concepción estructuralista y funcionalista y a depurar sus métodos. El libro capital de esta escuela, Principios fundamentales de la fonología, de N. Trubetzkoy, será pronto traducido y publicado en esta colección. Para las relaciones de la nueva fonología con Saussure ver la reseña de B. Terracini al libro de Trubetzkoy en la Revista de Filología Hispánica, 1942, IV, 173-180, y R. JAKOBSON, ob. cit. 
perturbaciones y destrucciones ciegas causadas por factores extrínsecos al sistema fonológico»; la colectividad se limitaría a dar un sentido al desorden, interpretándolo como un sistema ordenado. Pero el papel de la colectividad es mucho más activo; los golpes ciegos son raros, y siempre que hay un proceso destructivo va necesariamente seguido de una reacción activa. Hay cambios lingüísticos que -como los movimientos del ajedrez - «tienen la intención de ejercer una acción sobre el sistema». Cuando se discierne, con la nueva Fonología, entre diferencias significativas y diferencias puramente materiales, $\mathrm{y}$ en las significativas entre correlaciones $\mathrm{y}$ disyunciones, entre supresión de una diferencia o fusión de dos, entre aparición de una diferencia fonológica o modificación material de una ya existente, etc., entonces «lo que se impone al lingüista es la cuestión de la finalidad en un cambio fonético, en lugar de la cuestión tradicional de las causas. No superaremos la tradición de los Neogramáticos renunciando a la noción de "ley fonética", sino interpretándola teleológicamente y abandonando su concepción mecanicista» ${ }^{8}$. Atacado el principio de Saussure en su mismo centro - los cambios fonéticos-, la crítica ha conseguido dilucidar la cuestión también en los otros aspectos de la diacronía. Ya Saussure ponía junto a los efectos ruinosos del cambio fonético, los reconstructores de la analogía (pág. 186 y sigs.). «La analogía supone un modelo y su imitación regular. Una forma analógica es una forma hecha a imagen de otra o de otras muchas según una regla determinada» ${ }^{9}$.

Es, pues, evidente que las formas analógicas suponen un especial manejo del sistema, se deben siempre a reacomodaciones del sistema. Saussure llamaba a los neologismos fonéticos cambios, y a los analógicos creaciones ${ }^{10}$; pero unos y otros son hechos de diacronía, y los analógicos, ya tal como Saussure los comprendía, destruyen su principio propuesto: sin posible escape, las creaciones analógicas son a la vez sincronía y diacronía.

8 Actes du premier congrès international de Linguistes à La Haye (del $10 \mathrm{al} 15$ de abril 1928). Leiden, s. a., págs. 3336. Al año siguiente los fonólogos del Cercle Linguistique de Prague subrayaron y complementaron su doctrina en una tesis presentada colectivamente al Primer Congreso de Filólogos Eslavos: «La concepción de la lengua como sistema funcional es la que ha de mantenerse también en el estudio de los estados de lengua pasados, ya se trate de reconstruirlos, ya de anotar su evolución. No es admisible poner barreras infranqueables entre los métodos sincrónico y diacrónico, como hace la escuela de Ginebra. Si en lingüística sincrónica se consideran los elementos del sistema de la lengua desde el punto de vista de sus funciones, no será posible ya interpretar los cambios sufridos por la lengua sin tener en cuenta el sistema que resulta afectado por tales cambios. No es lógico suponer que los cambios lingüísticos no sean más que golpes destructivos dados al azar y heterogéneos respecto del sistema. Los cambios lingüísticos apuntan con frecuencia al sistema, a su estabilización, a su reconstrucción, etc. Así el estudio diacrónico, lejos de excluir las nociones de sistema y de función, es incompleto si no se tienen en cuenta esas nociones. Por otra parte, la descripción sincrónica tampoco puede excluir del todo la idea de evolución, pues aun en un sector visto sincrónicamente existe la conciencia de estado caduco o en vías de desaparición, de estado presente y de estado en formación; los elementos estilísticos sentidos como arcaísmos y la distinción entre formas productivas y no productivas son hechos de diacronía, que no se podrán eliminar de la lingüística sincrónica». Travaux du Cercle Linguistique de Prague, I, Praga, 1929, págs. 7-8. Insiste ROMAN JAKOBSON en su citado artículo La scuola lingüistica di Praga, y en sus Prinzipien der historischen Phonologie (Travaux du Cercle Linguistique de Prague, 4, 1931), págs. 247 y sigs.

9 Pág. 186. El latín honor es forma analógica; primero era honos: honosem; después, por rotacismo de la -s- (que no alcanzaba a la -s), honos: honorem; por fin, conforme al modelo orator: oratorem, se produjo honor: honorem. 10 La dualidad cambio fonético: analogía era otra de las manejadas por los Neogramáticos. Saussure ahondó estos conceptos con rigor nuevo y, según su estilo, los presentó como antinomia irreductible. Pero Vossler la redujo: todo cambio fonético empieza en el individuo; el individuo es quien en cierta ocasión, en determinada palabra, realiza una alteración fonética, por ejemplo, pronunciando mŏla no ya móóla según el uso general (óó representa convencionalmente una sola ó prolongada y homogéneamente abierta), sino móóla, apretando un poco más la articulación al principio. (Éste es el cambio que, proseguido en las generaciones siguientes, llevará 
Y no sólo las creaciones analógicas. Otro gran innovador suizo-francés, Jules Gillieron, el autor del Atlas linguistique de la France y de los más apasionantes estudios sobre los materiales del Atlas (y de las más apasionadas polémicas sobre sus estudios) ${ }^{11}$, al querer destruir el concepto lingüístico de cambio fonético - lo que no pudo pasar de una pretensión-, opuso una masa de hechos que, traídos a nuestro problema, contradicen la oposición saussureana entre sincronía y diacronía: la etimología popular (opuesta a la etimología fonética), los calcos lingüísticos, la evitación de homonimias, las reacciones fonéticas, las regresiones, etc.; alteraciones todas que tanto en la finalidad como en la operación de cumplimiento cuentan con el sistema en cuyo seno se realizan. Contra el principio de Saussure, la diacronía se genera en la sincronía.

Éste es el aspecto puesto también al descubierto por B. Terracini, op. cit., y especialmente por Walter von Wartburg ${ }^{12}$ : los métodos geográfico lingüísticos de Gillieron, su ingenioso husmeo de conflictos de nominación y su solución dentro del sistema de orientación para comprender el paso de una sincronía a una diacronía; pero Gillieron, con materiales exclusivamente geográficos, sólo supo ver las fuerzas condicionantes de la necesidad (remedio de las insuficiencias de la lengua); si otro género de materiales (y otra ideología menos limitada que el positivismo, añado) le hubieran permitido ver el funcionamiento de las fuerzas libres del espíritu (afectividad, humor, juegos de la fantasía), Gillieron habría sorprendido también el paso dé la diacronía a la sincronía, llegando a una representación más satisfactoria de la vida del lenguaje. Cada palabra depende de su grupo semántico, no sólo en el funcionamiento sincrónico del sistema (Saussure), sino en la aparición del cambio; y, a la inversa, los grupos semánticos se reordenan con las innovaciones (negación del principio de Saussure). Partiendo von Wartburg de la recíproca situación semántica de las palabras, que es precisamente el principio saussureano del sistema solidario, orienta sus investigaciones históricas hacia la participación del sistema en los cambios: «El destino de las palabras, su florecimiento y proliferación, su progresivo extinguirse y su muerte, la manera en que otras palabras las sustituyen, todo está en gran parte condicionado por el modo como ellas se encuentran dentro de su contorno o ambiente» (Betrachtungen, 304).

Ante un ataque tan persistente y general, «los raros mantenedores de la ortodoxia saussureana se ven reducidos a la defensiva», como dice el más

a muola, muela). Pero el tal individuo desconocido no tuvo que repetir su invención con cada palabra del léxico, sino que, una vez aceptado por las gentes el procedimiento, se extiende por analogía a todas las palabras donde la o esté en las mismas condiciones (en Francia e Italia, acentuada y en sílaba libre; en España acentuada no más). El cambio fonético no existe hasta que la analogía lo generaliza; lo que las leyes fonéticas tienen de regularidad es de índole analógica. Cfr. KARL VOSSLER, Filosofía del lenguaje, pág. 83.

Para nosotros la superación de esta antinomia (cambio fonético: analogía) anula a su vez, por otro camino que el de los fonólogos, la antinomia diacronía: sincronía, porque, así dispuestos los hechos, se comprueba que no todo es desorden en el cambio fonético, como veía Saussure.

11 L'aire clavellus d'après L'Atlas Linguistique de la France, Neuveville, 1912. Généalogie des mots qui désignent l'abeille d'après l'Atlas Linguistique de la France, Paris, 1917. Pathologie et thérapeutique verbales, Paris, 1921. Les étymologies des étymologistes et celles du peuple, Paris, 1922. Thaumaturgie linguistique, Paris, 1923.

12 Das ineinandergreifen von deskriptiver und hiatorischer Sprachwissenschafi (La compenetración de la lingüística descriptiva y de la histórica). Berichte über die Verhandlungen der Sächsischen Akademie der Wissenschaften zur Leipzig, Philologische Klasse. Tomo 83, 1931, cuaderno 1. Estudio suplementado años más tarde con otro, que patentiza el camino inverso: Betrachtungen über die Gliederung des Wortschatzes und die Gestaltung des Wörterbuchs (Consideraciones sobre la articulación del léxico y la estructuración del diccionario), en Zeitschrift für Romanische Philologie, 1937, LVII, págs. 296-312. 
estricto de ellos, Albert Sechehaye. En realidad se baten en honrosa retirada ${ }^{13}$. Sechehaye admite los cambios «orgánicos» (generados en el sistema), pero, como siguen en pie otros «contingenciales», provocados por rebotes fortuitos ${ }^{14}$, el fiel discípulo de Saussure concluye que ambas tesis caben sin excluirse. Pero el principio saussureano de incompatibilidad queda con eso abandonado.

Después de estas críticas y de su aceptación ¿queda rebajada en su valor la distinción saussureana entre diacronía y sincronía? Al contrario, queda rectificada y depurada. Sigue en su plena validez el doble punto de vista para el doble estudio; en el sincrónico, el del hablante, que vive internamente el funcionamiento de su lengua; en el diacrónico, el externo del historiador, que contempla sus transformaciones sucesivas. Al abandonar el principio de Saussure, Bally, op. cit. pág. 60, aspira como programa mínimo a mostrar la «utilidad didáctica» de la aplicación separada de los dos métodos. No sólo por utilidad didáctica, sino por necesidad científica, afirmamos nosotros, distinguirá siempre la lingüística entre diacronía y sincronía. Sólo que al demostrar ahora su punto de convergencia, la antítesis postulada por Saussure queda positivamente superada. El destino de la otra famosa antinomia, la de lengua y habla, está implicado en el de diacronía y sincronía, como que la inconexión de éstas se basaba en la postulada inconexión de lengua y habla.

La importancia del discernimiento de estos dos aspectos del lenguaje es incalculable: la operatoria del funcionamiento de un idioma y la de su evolución, los modos de insertarse la libertad del estilo en las convenciones de la gramática y los modos de alterarse las convenciones del sistema conforme los actos individuales de estilo triunfan y se generalizan, la vida entera del lenguaje, en fin, se puede comprender con más profundidad y con mayor seguridad gracias a esta dualidad de conceptos. Sólo que el Curso sacrifica otra vez, a las conveniencias de un método rigurosamente positivo ${ }^{15}$, el verdadero papel que la lengua y el habla desempeñan en el fenómeno humano del lenguaje. Saussure buscaba como primer imperativo un terreno

13 Charles Bally, En été: au printemps; croire en Dieu: croire au diable, en la Festschrift für Ernst Tappolet, Basilea, 1935, pág. 9 y sigs., contestando a E. Lereh; y Synchronie et diachronie, en Vox Romanica, 1937, II, pág. 53 y sigs., contestando a W. v. Wartburg. ALBERT SECHEHAYE, Évolution organique et évolution contingentielle, en Mélanges Bally, Ginebra, 1939, págs. 19 y sigs., y Les trois linguistiques saussuriennes, en Vox Románica, 1940, $\mathrm{V}$, pág. 1 y sigs., ambos artículos contestando a W. v. Wartburg, el primero plenamente y el segundo como punto de partida para desarrollar su idea. En el I Congreso Internacional de Lingüistas, La Haya, 1928, Bally y Sechehaye habían presentado juntos una ponencia en la que reafirmaban el principio de Saussure (Actes, 3653); pero el principio hizo crisis entonces, gracias a la citada ponencia de los fonólogos de Praga.

14 La expresión del número en el alemán Hand: Hände, ingl. foot: feet. Ya lo había concedido el opositor TERRACINI, Paleontología, 633, aunque con la observación de que los fortuitos (los saussureanos) eran siempre excepción.

15 «En efecto, entre tantas dualidades, la lengua parece ser lo único susceptible de definición autónoma y es la que da un punto de apoyo satisfactorio para el espíritu» pág. 37. «Tomado en su conjunto, el lenguaje es multiforme y heteróclito; a caballo en diferentes dominios, a la vez físico, fisiológico y psíquico, pertenece además al dominio individual y al social; no se deja clasificar en ninguna de las categorías de los hechos humanos, porque no se sabe cómo desembrollar su unidad» (Ib.). «La lengua, distinta del habla, es un objeto que se puede estudiar separadamente (pág. 42). «La lengua... es clasificable entre los hechos humanos, mientras que el lenguaje no lo es»; como sistema de signos que expresan ideas, formará parte de una ciencia más amplia, la semiología o teoría general de los signos, juntamente con otros sistemas, como «la escritura, el alfabeto de los sordomudos, los ritos simbólicos, las formas de cortesía, las señales militares, etc. etc». (págs. 43-44). «El conjunto global del lenguaje es incognoscible porque no es homogéneo, mientras que la distinción y la subordinación propuestas lo aclaran todo» (pág. 46). Subrayamos nosotros. 
firme donde practicar la investigación según principios y métodos también firmes; y de todos los aspectos del lenguaje, sólo la lengua se lo ofrecía. Porque las lenguas son sistemas de signos en donde nada cuenta sino los valores marcados por diferencias; un juego de correspondencias y oposiciones, sistemas extraindividuales, de existencia sólo social. La ciencia estudiará esos sistemas, sus elementos componentes y el juego de sus relaciones. Ése será «el objeto a la vez integral y concreto de la lingüística». El habla, en cambio, como individual, es heterogénea en sí. «La actividad del sujeto hablante debe estudiarse en un conjunto de disciplinas que no tienen cabida en la lingüística más que por su relación con la lengua. El estudio del lenguaje comporta, pues, dos partes: la una, esencial, tiene por objeto la lengua...; la otra, secundaria, tiene por objeto la parte individual del lenguaje, es decir, el habla, incluida la fonación» (pág. 45). Todo lo que no es el sistema mismo es externo a la lengua: en la sincronía, la actividad espiritual y fisicofisiológica de los hablantes; en la diacronía, todas las relaciones que puedan existir entre la historia de una lengua (como mero sistema de signos) y la historia cultural del pueblo.

Esas relaciones podrán ser muy importantes, pero sólo se admiten en calidad de conocimientos ilustrativos y sobreañadidos. La ordenación resultante es ésta: el estudio sincrónico del sistema tiene la primacía; es más, es el único estrictamente lingüístico, a) porque el habla, como individual es asistemática, y como ejecutora de la lengua le es ajena ${ }^{16}, b$ ) porque aun la lingüística diacrónica es lingüística a medias, ya que el objeto legítimo es la lengua como sistema, y los cambios (objeto de la lingüística diacrónica) no se producen para Saussure directamente en el sistema, sino en sus elementos aislados, que, de rebote, pueden traer al sistema consecuencias fortuitas ${ }^{17}$.

Esta ordenación de la ciencia y subordenación de sus partes se sustenta en el principio de que «la lengua» tiene una existencia concreta autónoma, independiente del «habla». Y ¿dónde se encuentra tal realidad? Saussure lo dice, pág. 39 y sigs. Al analizar el circuito del habla, contamos: $1^{\circ}$, en el cerebro de A un concepto asociado a una imagen acústica; $2^{\circ}$, el cerebro trasmite la orden de ejecución a los órganos fonadores y articuladores, y éstos la cumplen; $3^{\circ}$, las ondas sonoras van de la boca de $\mathrm{A}$ al oído de $\mathrm{B} ; 4^{\circ}$, en $\mathrm{B}$, la excitación del oído corre al cerebro; $5^{\circ}$ «en el cerebro, asociación psíquica de la imagen con el concepto correspondiente». La lengua, discurre Saussure, no está en la parte ejecutiva $\left(1^{\circ}\right.$ y $\left.2^{\circ}\right)$, siempre individual; tampoco en la parte física $\left(3^{\circ}\right)$ ni en la transmisión fisiológica $\left(4^{\circ}\right)$; la lengua «se puede localizar en la porción determinada del circuito donde una imagen acústica viene a asociarse con un concepto»: en el punto $5^{\circ}$ (pág. 42).

Esta representación del acto coloquial, tan sugestiva didácticamente por sus seguros deslindes, es hoy insostenible en sus dos estaciones terminales.

Es más, está fuera de la doctrina saussureana de la articulación, olvidada cuando mayor servicio le podía dar, y en realidad es un resabio del asociacionismo herbartiano de los Neogramáticos, tan tenazmente combatidos

16 Claro que «hay interdependencia de lengua y habla; aquélla es a la vez el instrumento y el producto de ésta. Pero eso no les impide ser dos cosas absolutamente distintas» (pág. 46). Este capítulo IV de la Introducción se titula «Lingüística de la lengua y lingüística del habla», y en él se concede que se puede hablar de una lingüística del habla, pero sin confundirla con la lingüística propiamente dicha, la de la lengua.

17 «Se suele decir que nada es tan importante como conocer la génesis de un estado dado; es verdad en cierto sentido: las condiciones que han formado ese estado aclaran su verdadera naturaleza y nos libran de ciertas ilusiones; pero eso justamente es lo que prueba que la diacronía no tiene su fin en si misma. Se puede decir de ella lo que se dice del periodismo: que lleva a todas partes, a condición de que se le deje a tiempo» (pág. 165). Saussure combatía aquí contra los Neogramáticos, que veían esencialmente la lengua como el producto acumulado de la historia de su comunidad. 
por Saussure en otros puntos menos dignos de oposición ${ }^{18}$.

Pues esa doctrina de la «articulación» ya excluye la posibilidad de explicar la iniciativa del hablar y su cumplimiento por operaciones sumadas de asociaciones entre una idea y su palabra. La «lengua» consiste en un instrumental numerable capaz de expresar pensamientos innumerables. La «lengua» no encierra previamente en su sistema el pensamiento concreto que por su intermedio voy ahora articulando; encierra, sí, los procedimientos de articulación - unos pocos, válidos para todos los pensamientos posibles - y también una nomenclatura (que ya nos presenta la realidad reducida a clases) de la que voy entresacando los nombres para los artejos de mi pensamiento. El pensamiento que articulo idiomáticamente no pierde su unidad originaria en la articulación, sino que es el pensamiento unitario original el que mi espíritu sigue manteniendo presente a través de su articulación. Este pensamiento no se puede expresar por asociación con palabra alguna, y por eso precisamente lo tengo que articular ${ }^{19}$.

El asociacionismo negado para el momento $1^{\circ}$ tampoco es real en el momento $5^{\circ}$, el de la comprensión. El comprender lo que a uno le dicen está lejos de ser una operación pasiva y mecánicamente asociadora ${ }^{20}$.

Comprender - un poema o una frase coloquial - requiere cierto modo de recreación. Supone, por lo pronto, la conciencia de que el hablante no emite meros sonidos sino que en él actúa la «intención» de dar sentido, de hablarle ${ }^{21}$; un punto rigurosamente del habla (momento $1^{\circ}$ ) lo sorprendemos instalado constitutivamente en el momento $5^{\circ}$, supuesto asiento de la lengua. El que escucha no se limita para comprender a registrar pasivamente los elementos idiomáticos que le van llegando y a asociarlos con las ideas correspondientes; el acto de la comprensión supone una conciencia

18 Como que casi parece elaboración brillante de un pasaje de Hermann Paul, el teórico de los Neogramáticos, al desechar el concepto de un espíritu colectivo, y asentar que la llamada Völkerpsychologie sólo puede consistir en relaciones entre espíritus individuales, no directas, sino a través de medios físicos: «Para que un alma en cuyo seno nace un complejo de representaciones lo despierte en otra, no puede hacer otra cosa que, por intermedio de los nervios motores, generar un producto físico, que, a su vez, mediante la excitación de los nervios sensitivos de los otros individuos, despierta en su alma las representaciones correspondientes y correspondientemente asociadas. De entre los productos físicos que sirven a estos fines, los más importantes son los sonidos idiomáticos. Otros son los tonos, y luego los gestos, ademanes, etc. ». En su concepción asociacionista (base para Saussure de la autonomía de la «lengua» y de su primacía como objeto de la lingüística) insiste Hermann Paul a continuación: «Lo que hace que estos productos físicos sirvan de instrumento para la transmisión de representaciones a otro individuo es, o una relación interna y directa con las representaciones correspondientes (piénsese, p. ej. en un grito de dolor, un gesto de furia) o una conexión debida a asociación de ideas [destacado por H. Paul], donde también la representación basada en la relación directa con el instrumento físico forma el lazo de unión entre el instrumento y la representación comunicada; éste es el caso del lenguaje». HERMANN PAUL, Prinzipien der Sprachgeschichte, 1880, § 7. Cito por la $5^{\circ}$ edición, Halle, 1920, página 14.

19 La psicología asociacionista hace medio siglo que ha dejado de prestar servicios a la ciencia. En cuanto al lenguaje, el carácter creador del «habla» ya está casi explícitamente concedido por el mismo Saussure, cuando lo llama «acto individual de voluntad y de inteligencia». Por supuesto, toda la orientación espiritualista de nuestra ciencia subraya la natuleza creadora del hablar: Vico, Herder, Humboldt, Croce, Vossler, Stenzel, Cassirer, etc. Citaré algunos títulos de por sí explicativos: H. v. KLEIST, Ueber die allmähliche Verfertigung der Gedanken beim Reden (Sobre el gradual cumplimiento de los pensamientos al hablar); K. VOSSLER, El lenguaje como creación y evolución: E. CASSIRER, Le Langage et la constitution du monde des objets; etcétera.

20 «La lengua no es una función del sujeto hablante; es el producto que el individuo registra pasivamente; nunca supone premeditación, y la reflexión no interviene en ella mas que para la actividad de clasificar» (pág. 57).

21 Ya destacado por E. HUSSERL, op. cit., § 7. 
activa, una actitud como de sintonización con la actividad creadora del que habla, una respuesta psíquica adecuada. Este pensamiento unitario particular que yo articulo con los medios de mi idioma para ser transmitido a tu conciencia, provoca tu prurito de aceptación, lector amigo, por su contenido unitario, y a ese contenido es al que el ojo de tu conciencia se va acomodando tácticamente a través del instrumental sintáctico y léxico, como el ojo de tu cuerpo se va acomodando a los objetos enfocados a través de los lentes auxiliares. Mi articulación te sirve de punto de partida para reconstruir lo unitario y lo particular de mi pensamiento; pero la reconstrucción es tuya: tú eres quien vas reorganizando hacia lo unitario los materiales que linealmente te van llegando. Si el habla es un modo de creación, el comprender es sin escape posible un modo de recreación. El mero asociar no lo explica, porque el pensamiento ahora hablado no estaba previsto (ni ningún otro) en el sistema de signos que es la lengua. Saussure descubre luminosamente que el producir y armar tal pensamiento particular es cosa del habla, no de la lengua. Y tendremos que completar: tampoco es de la lengua, sino del habla, el momento de la comprensión $\left(5^{\circ}\right)$, que consiste en rearmarlo reorganizando su unidad. En conclusión: si ese punto $5^{\circ}$, esa zona asociadora del cerebro del oyente, es la residencia de la lengua, la lengua no existe como reino autónomo del habla, porque en esa $5^{\mathrm{a}}$ etapa reconocemos la presencia constitutiva de la actividad creadora o recreadora propia del habla. Podemos, sí, discernir lo individual y lo social en un idioma, pero cuando nuestro análisis se aplica con total responsabilidad a la existencia concreta de uno y otro elemento, reconocemos que la lengua sin habla no tiene existencia real en ninguna parte; sólo existe en el uso activo que de ella hace el que habla o en el uso activo del que comprende. Sólo el «habla» real da realidad a la «lengua» - . Esto obliga a ver en el habla y no en la lengua el gozne de la ciencia del lenguaje $\mathrm{e}^{22}$.

Mas poner en el «habla» el centro de los estudios lingüísticos es hacer girar todo el sistema positivista de Saussure y encuadrarlo en la orientación espiritualista. Y he aquí que los problemas técnicos planteados a propósito de las antinomias diacronía: sincronía y lengua: habla, se conviertende pronto en el problema filosófico central del lenguaje y de la lingüística. Pues la frase-bandera de Humboldt, «el lenguaje es esencialmente enérgeia, no érgon», actividad, no producto, equivale, en términos del Curso, a que el lenguaje es esencialmente «habla», no «lengua». Y ello compromete a prestar atención primordial a lo que de espíritu tiene el lenguaje.

Saussure rechaza muy hermosamente la concepción naturalista (Schleicher) de la lengua como un organismo de vida autónoma y de crecimiento y evolución internos; pero su positivismo le hizo suplantar esta concepción por otra mecanicista en la que la lengua es un sistema igualmente autónomo, ajeno al habla, fuera del alcance de sus hablantes, y que funciona gracias a un juego de asociaciones y correspondencias entre los términos mismos, como con mecánica sideral. El concebir tal autonomía del sistema era un postulado de la orientación positivista, que se creía obligada a mondar del objeto de la ciencia lo que fuera indeterminación, y, por consiguiente, todo lo que fuera espíritu con su libertad de iniciativa.

Por eso esta orientación pone tanto empeño en separar filología (en su sentido de interpretación de textos y de estilos individuales) y lingüística, y jerarquiza la lengua oral (espontánea, dice) sobre la literaria, artificiosamente elaborada. Y así como la autonomía del sistema permite al autor en la sincronía descartar del funcionamiento de la lengua el elemento motor (el espíritu individual,

22 Husserl, pág. 40, roza este punto, aunque ajeno a nuestro problema: tras de las frases arriba aludidas sobre que el oyente comprende en el otro la intención de dar sentido, de hablarle, añade: «El hablar y el oír, el notificar vivencias psíquicas con la palabra y el tomar nota de las mismas en la audición, hállanse en coordinación mutua». 
relegado al habla), así en la diacronía los cambios resultan involuntarios e inconscientes, incapaz el hablante de intervenir en el sistema para alterarlo ${ }^{23} ; \mathrm{y}$, en consecuencia, la evolución del sistema es igualmente autónoma, ajena en sí misma a la historia de la civilización del pueblo que lo usa; las relaciones entre ambas historias son meramente tangenciales, y constituyen la «historia externa» de la lengua ${ }^{24}$.

He aquí, pues, cómo, tanto del funcionamiento como de la evolución de una lengua, se consigue descartar la acción del espíritu. Por cierto que no es de sospechar en un Ferdinand de Saussure animadversión alguna contra el espíritu; en él no hay rastro alguno de materialista, ya que el sistema de la lengua no tiene existencia material, sino psíquica, aunque despersonalizada. Fue la aspiración del positivismo al «pájaro en mano» la que empujó a la clara inteligencia de un Saussure a simplificar su objeto de estudio, eliminando, por material indócil, todas las complejidades que no se adecuaran a los métodos disponibles, toda acción irreducible a relaciones previsibles entre elementos previstos.

Pero ahora, enmendando la dislocación del eje de la lingüística, goznándola sobre el habla y no sobre la lengua, nuestro objeto de estudio recobra su concreta complejidad; las antinomias de sincronía: diacronía, lengua: habla, cambio fonético: analógico, etc., quedan superadas, engranadas en su papel de dualidades funcionantes, como las dos piernas del andar (imagen de Vossler: cuando una pierna avanza la otra no está ociosa); la diacronía tiene no menor dignidad científica que la sincronía, y la acción del espíritu preside todo el funcionamiento y toda la historia de la lengua. Si la lengua es un sistema, ¿quién sino el espíritu de los hablantes lo ha hecho sistemático y lo mantiene como tal? Si todo cambio se origina en un hablante individual y se cumple mediante su adopción por la colectividad hablante ¿cómo podrán los cambios ser ciegos, inconscientes e involuntarios, qué sino la voluntad expresiva, qué sino la conciencia idiomática, quién sino el espíritu -con iniciativa intencional o por abandono - los ha podido iniciar, empujar y cumplir? Si la «lengua» como sistema sólo se pone a funcionar cuando el «habla» con su plus de dar sentido es el motor, ¿quién sino el espíritu del hablante es ese motor, quién sino el espíritu del oyente reconstruye el sentido concreto que con ayuda del sistema se expresa?

No pensemos que con esto arrinconamos la lingüística de Saussure y abrazamos otra tendencia. Estamos esforzándonos en presentar la doctrina misma del Curso y en alargar sus líneas por donde y hasta donde la crítica ha comprobado. ¡Quién sabe hasta dónde las habría prolongado o hacia dónde rectificado el mismo Saussure si la muerte le hubiera dado el tiempo que su conciencia tan escrupulosa requería, si él mismo hubiera por lo menos escrito su libro! Y sobre todo, si, escrito por él y publicado, hubiera tenido ocasión de participar en las pruebas y contrastaciones a que la crítica ha ido sometiendo sus doctrinas. Casi al mismo Saussure podemos acreditar todas las superaciones de sus teorías

23 Por fortuna la crisis abierta por Saussure sobre este punto parece ya resuelta, pues Albert Sechehaye, uno de los redactores del Curso y el más celoso guardián de la ortodoxia saussureana, ha reconocido la necesidad de rectificar al maestro (Les trois linguistiques saussuriennes, 1940). Y ha sido precisamente la demostración de error para el otro principio, el de la inconexión entre diacronía y sincronía, lo que ha obligado a un Sechehaye a reordenar la materia toda. Saussure - reconoce el fiel Sechehaye - erró en ese principio por aferrarse al de la primacía de la «lengua» entre todos los aspectos del lenguaje: pero el «habla» es la que resuelve la antinomia diacronía: sincronía, porque participa de ambas, como que se funda en un estado de lengua y contiene en esencia el germen de todas las transformaciones futuras (op. cit., pág. 7). No hay la reciprocidad supuesta por Saussure: la lengua nace del habla, no al revés; el habla no es el mero funcionamiento de la lengua, tiene un plus; el elemento motor y director del acto que cumple: «Au commencement était la parole» (pág. 9). La lingüística estática de la lengua se tiene que encajar en la del habla para comprender satisfactoriamente la vida del lenguaje (pag. 10).

24 Bally, que repetía la doctrina de Saussure en la primera edición de Le langage et la vie, en las siguientes la mitiga: «en gran parte involuntarios e inconscientes». 
aquí apuntadas: la nueva fonología, aunque explícitamente negada en el Curso, está en él implícitamente postulada; y sus tres más devotos discípulos patrocinan las otras rectificaciones: Meillet, vivificando la historia lingüística con la historia dela civilización; Bally, insuflandola vida real, individual y social, en el funcionamiento del sistema ${ }^{25}$, y Sechehaye, reconociendo que la irreducción de las antinomias se salva centrando la lingüística en la omnipresente «habla» y no en la «lengua».

Para mejor, las prolongaciones y rectificaciones de las ideas de Saussure no han dañado lo más mínimo a la eficacia de sus métodos científicos, tan magistralmente elaborados. Las distinciones que Saussure vio en el fenómeno del lenguaje y en la ciencia que lo estudia siguen siendo las que nosotros discernimos, y los métodos que él propuso siguen siendo los más rigurosos, si bien no los únicos. Sólo en los extremos, en los puntos de contacto de sus antinomias, la prueba crítica lo ha desmentido: lo que él pensó que eran cosas diferentes se comprueba tan sólo como aspectos diferentes de un objeto unitario. Sólo la jerarquización de esos aspectos, no su existencia, ha tenido que ser rectificada. $Y$ con esta colaboración de muchos, el libro del insigne maestro de Ginebra, que ya nació como obra de varios, multiplica sus virtudes originarias: la de fecundar el pensamiento lingüístico en las teorizaciones y la de proporcionar los métodos adecuados para la investigación particular.

25 Ya Antoine Meillet, el más ilustre de los secuaces de Saussure, declaro al reseñar el Cours (Bull. Soc. Ling. Paris, 1916. XX, pag. 35) que la doctrina saussureana, ceñida exclusivamente al aspecto sistemático de la lengua, era demasiado abstracta, sin la necesaria atención a la realidad humana e histórica en que la lengua nada y vive. En su obra, larga y magistral, el saussureano Meillet no cayó en tal descarriamiento; lo salvó la tradición de su otro gran maestro, Gaston Paris, para quien la historia de una lengua era inseparable de la historia de la civilización de sus hablantes. 